\title{
Geocentrismo, Antropocentrismo e Heliocentrismo
}

\author{
A. M. AMORIM DA COSTA *
}

Confrontados com o acaso que reina no interior da matéria, os cientistas tiveram de proceder ao estabelecimento de uma nova visão da realidade, mas não ficaram minimamente cerceados, nem impossibilitados, no prosseguimento da sua missão científica.

"A verdadeira Física é a que conseguirintegraro Homemtotalnuma representação coerente".

Teilhard de Chardin

1. DEUS, 0 HOMEM E 0 UNIVERSO

Toda a actividade científica aponta no sentido da humanização da Terra. 0 homem, pelo progresso técnico, tenta fazer desaparecer dela tudo quanto lhe é prejudicial e criar as melhores condições para a sua sobrevivência e afirmação. A sua pequenez física, um nada na vastidão física do universo em que está inserido, não inviabilizou nunca a gigantesca tarefa que pelo progresso técnico se propōe. No intelecto reside o seu grande poder, a sua indomávelforça de domínio que the permite ser, de facto, esse rei e senhor do mundo em que vive que para sireclamam, de há séculos a esta parte, tanto os homens da Bíblia como a maioria das mais primitivas religiões: 0 universo exterior a Deus existe para o Homem, neste se encontrando o seu centro natural, donde tudo dimana e a que tudo se orienta; tudo começou pelo Homem; tudo continua por ele e para ele; e tudo nele deve acabar.

"Então disse Deus: façamos o Homem à nossa imageme semelhança. Que ele reine sobre os peixes do mar, os pássaros dos céus e os animais domésticos, sobre toda a terra e sobre todos os répteis que nela se arrastam. $E$ Deus criou o Homem à sua imagem, homem e mulher, e os abençoou dizendo: crescei e multiplicai-vos; enchei a Terra e submetei-a; dominai sobre os peixes do mar, as aves do céu e todos os animais da Terra. Vossa é toda a erva que dá semente e vossas são todas as árvores frutíferas para que vos sirvam de alimento" (1).

$\mathrm{Na}$ Natureza tudo se referencia em função do Homem; é a antropomorfização da Natureza. 0 panteísmo que tudo referencia em função do cosmos, numa cosmificação da Natureza, em geral, e do Homem, em particular, é uma elaboração cultural relativamente tardia.

Ser inteligente, o Homem especulou, ao longo de milénios, sobre a natureza e a origem do Universo. A antropocosmologia foi, desde o dealbar da atitude teorética, o tema central da sua meditação filosófica, na certeza de que "tudo aquilo que é cosmológico concerne ao homem; e tudo aquilo que é antropológico concerne essencialmente ao cosmos", como bem o notou Edgar Morin. Antropocentrismo e geocentrismo são as características fundamentais e estreitamente ligadas entre si, da primeira visão que para si construiu do cosmos, alicerçada na concepção dos mais influentes filósofos da Antiga Grécia, ciosa e autoritativamente tidos como mestres indiscutiveis até finais da Idade Média. De Aristóteles ao Renascimento do século XVI, pese embora o esporádico de uma que outra voz discordante, o Homem acreditou que a Terra é imóvel. A causa da sua imobilidade estaria na sua gravidade nativa. Porque esta seria a máxima possivel, a Terra desde sempre terá desejado o lugar mais distante do céu, ou seja, o meio do mundo; pelo seu próprio ímpeto, associado à sua própria gravidade, assim o realizou e aí repousaria fixa, não podendo de lá ser tirada para outro lugar senão pela violência (2).

Muito antes de Aristóteles, logo nos alvores do pensamento grego, Anaximandro deixara-o bem claro: a Terra encontra-se em equilibrio no centro do Universo, e não cai para qualquer dos lados, exactamente porque está localizada simetricamente em relação a tudo quanto a rodeia.

Centro do Universo, a Terra é o habitáculo sagrado do Homem "medida de todas as coisas" (Protágoras) e a que todas as coisas estariam naturalmente ordenadas, alvo de todas as predilecções e cuidados do ser supremo, que nele teria sempre postas todas as suas atenções. No Universo, 0 Homem ocuparia, pois, no mundo geocêntrico da filosofia de Aristóteles, um lugar de privilégio, simultaneamente como ser vivo e como ser inteligente; nele, o seu conhecimento intelectual atingiria o próprio princípio das coisas, a causa e razão última do seu devir, 0 fim que as habita e organiza (3).

Geo - e antropocêntrico, o universo de Aristóteles seria estático e fechado. Estático, no sentido de que se mantinha idêntico a si mesmo e invariável no seu todo, do primeiro ao último instante da sua existência; fechado, porque um todo finito e bem ordenado, com uma estrutura espacial em que tudo está devidamente hierarquizado, onde reinam a coerência, a beleza, a perfeição. Para além da região sub-lunar de mudança e corrupção, onde se encontra a Terra pesada e opaca, estão as esferas celestes dos astros imponderáveis, incorruptiveis e luminosos, circunscritas pela esfera última das estrelas fixas.

Esta imagem do Universo começa a ser posta em causa pelos fins da Idade Média. Ao homem é negado o lugar de privilégio por ela afirmado. Muito antes mesmo do heliocentrismo proclamado por Copérnico, ganhou terreno a ideia de um universo sem qualquer centro físico. 0 geocentrismo foi arduamente confrontado com a ideia do sine-centrismo, a ideia de um universo sem qualquer centro físico.

Pioneiro, Nicolau de Cusa (1401-1464) declarou-o peremptoriamente: 0 universo não tem qualquer centro físico, mas tão somente um centro metafísico, o seu princípio e fim, o seu fundamento e limite, o próprio Deus, ser absoluto, de que é expressão (explicatio) imperfeita e inadequada, no reino da multiplicidade e da separação. Metafísico, este centro não 


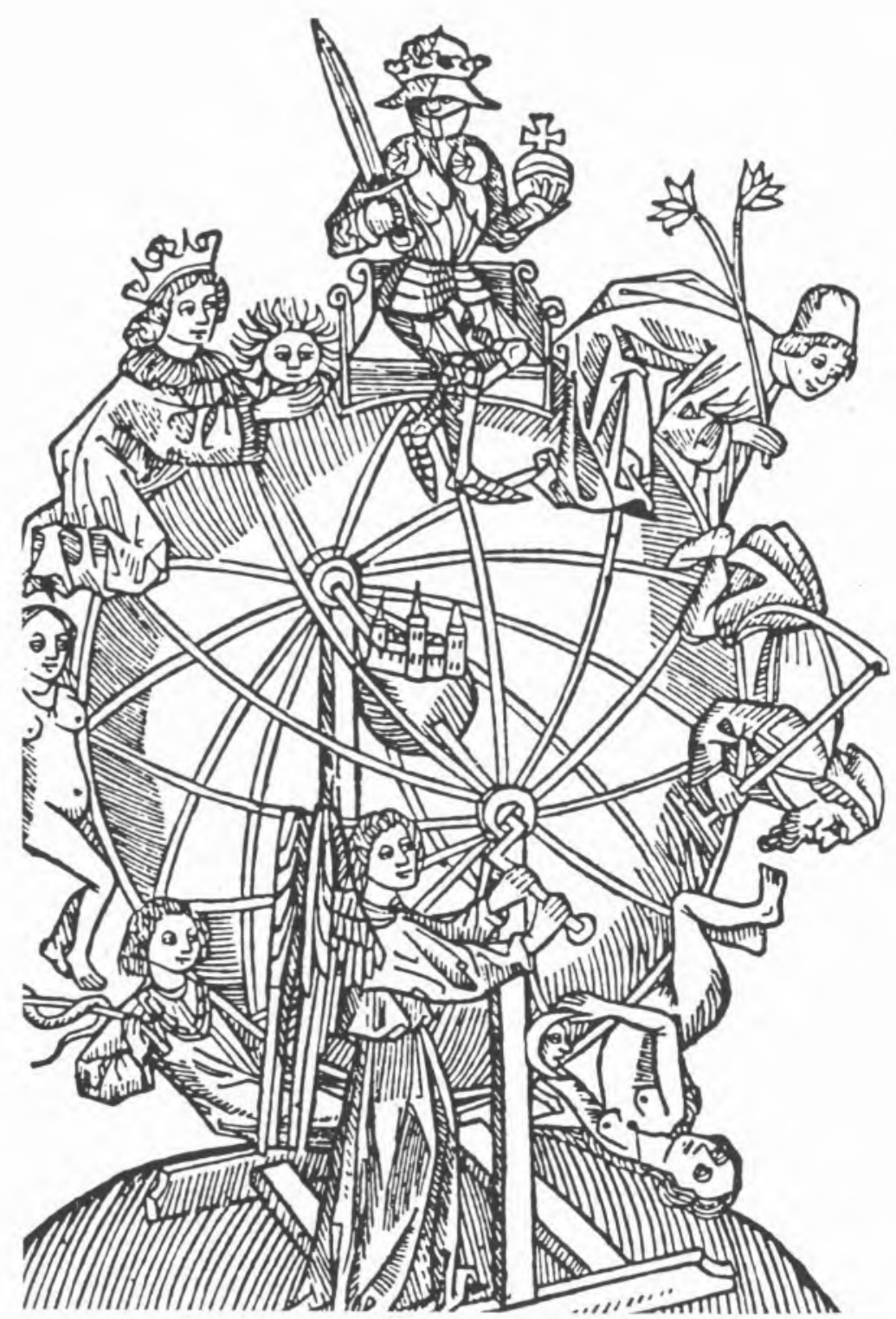

pertence ao mundo: "é impossivel que a máquina do mundo tenha um centro fixo e imóvel, quer este seja esta terra sensível, ou o ar, ou o fogo, ou não importa qualquer outra coisa". Com efeito, sendo o centro um ponto equidistante da circunferência, o centro do mundo nunca poderia estar no interior da terra, nem fora dela, já que uma equidistância precisa a tudo quanto existe não pode ser encontrada fora de Deus, que só Ele é a igualdade infinita. Só Deus pode ser o centro da Terra e de todas as esferas celestes, assim como de tudo o que está no mundo. Porque não tem qualquer outro centro que não seja o próprio Deus, o mundo não tem também circunferência, ou, por outras palavras, centro único do mundo, Deus é também a circunferência infinita de todas as coisas: "o mundo não tem circunferência. Porque se tivesse um centro ele teria também uma circunferência, e assim teria em si próprio o seu começo e o seu fim, e estaria limitado em relação a algo de outro; assim, fora do mundo haveria algo de outro, e espaço, coisas que carecem de toda a verdade. Como, portanto, não é possível encerrar o mundo entre um centro corporal e uma circunferência, não podemos compreender o mundo de que o centro e circunferência são Deus" (4).

Assim entendido, o Universo não estaria "contido" na carapaça ex- terior das esferas celestes, como não seria um Universo "terminado" nos seus constituintes, isto é, careceria de todo de precisão e determinação rigorosas (5). Nem a Terra, nem outra coisa qualquer podem estar colocados no centro do Universo, pura e simplesmente porque tal centro não existe fisicamente. Não há estrelas situadas exactamente sobre os polos ou sobre 0 equador da esfera celeste; não há eixos fixos e constantes. Nada neste mundo pode estar completa e absolutamente em repouso.

Neste sinecentrismo físico do Universo proclamado por Nicolau de Cusa encontramos o primeiro passo no sentido da afirmação de um universo infinito, desprovido de coerência e caracterizado por uma extensão infinita e homogénea. Com ele se começa a definir a ideia de um universo aberto $e$ infinito, um universo onde o homem está entregue a si mesmo, ao seu livrearbitrio, aos seus valores morais, cabendo a cada um "escolher o seu deus e o seu demónio" (6) que a ciência moderna acabaria por assumir.

Neste universo sem centronem direcção privilegiada, a Terra passaria, pouco a pouco, a ser considerada como um pequeno fragmento entre muitos outros de valor idêntico, ou mesmo superior. Ganhou foros de simplista a ideia de que a Terra é única, como objecto individual sem paralelo em qualquer ponto do universo, em singularidade capaz de exigir uma morada especial. $\mathrm{Na}$ extensão infinita e homogénea do universo ilimitado e povoado por toda a parte, deixa de haver lugar para qualquer hierarquia natural de valor, perfeição ou harmonia, na multiplicidade dos corpos que o compõem; todos são colocados no mesmo nivel ontológico, num espaço que não é mais um conjunto diferenciado de locais intramundanos, mas antes o espaço geométrico euclidiano, idêntico, na sua estrutura, ao espaço real do universo (7). No seu género, a Terra é tão perfeita quanto o sol e as estrelas fixas nos céus (8).

Esta deslocação da Terra do centro do mundo, negando ao homem uma posição única e privilegiada no drama teocósmico da criação não fo sentida, a princípio, como uma degradação. Para Nicolau de Cusa, a infinitização do Universo envolvia mesmo a promoção da Terra à categoria das estrelas nobres: "a Terra é, 


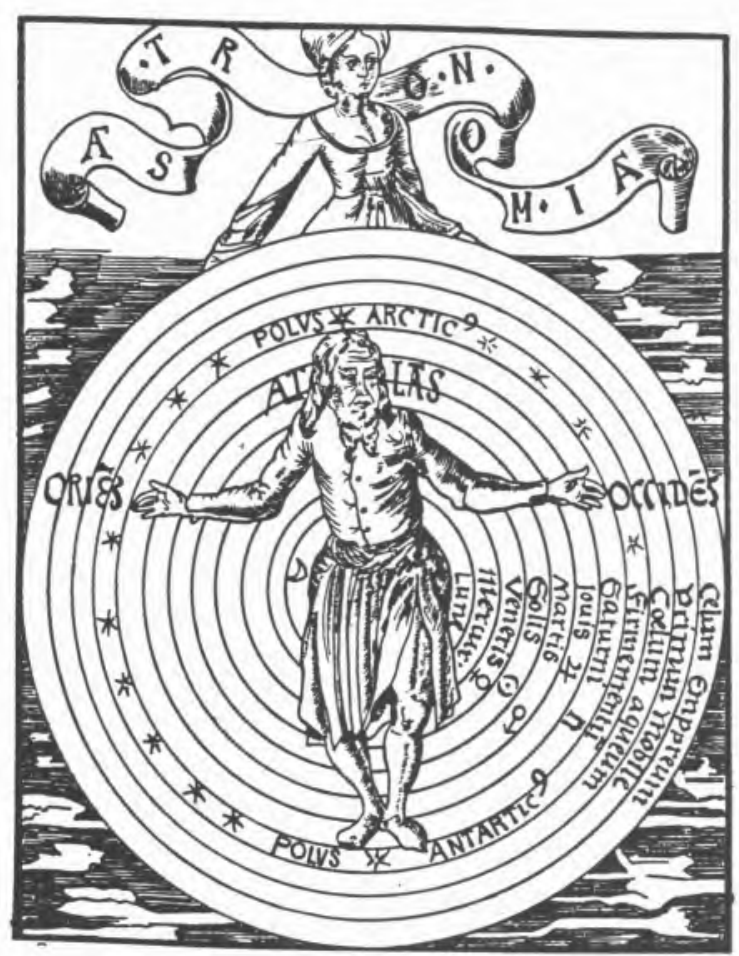

portanto, uma estrela nobre que tem uma luz, um calor e uma influência próprias e distintas das de todas as outras estrelas; assim como cada uma delas, difere de todas as outras em luz, em natureza e em influência" (9).

De igual modo, para Giordano Bruno (1548-1600), a dispersão das esferas das estrelas fixas representava a abertura do homem aos tesouros inesgotáveis do universo eterno e ilimitado, onde o movimento e a mudança permanentes seriam sinais de perfeição e vida. Ao contrário do que pensavam os Antigos, segundo Giordano Bruno, o universo para ser vivo deve poder mover-se e mudar; um universo imutável seria necessariamente um universo morto: "não existem termos, limites, margens, muralhas que nos defraudem e roubem a infinita cópia das coisas. Daí, ser fecunda a terra e o seu mar; dai ser perpétua a chama do sol, subministrando eternamente alimento aos fogos vorazes, e humores aos mares empobrecidos, porque do matéria" (10). 0 mundo finito compreenderia somente a perfeição de todas as coisas finitas que estivessem no seu espaço, mas nunca a das coisas infinitas que pudessem existir noutros espaços inumeráveis (11).
Tornada obsoleta, do ponto de vista ontológico, a distinção entre os vários mundos que constituem o universo, nomeadamente o mundo celeste e o mundo terrestre, e afirmada a impossibilidade de atribuição de um limite ao universo, o homem perdeu inevitavelmente a condição de posição única e privilegiada que até então lhe fora reconhecida. 0 centro do universo estaria em toda a parte e a sua circunferência em parte alguma e, consequentemente, a designação de centro passaria a convir, de igual modo, a cada mundo particular, a cada estrela, a cada sol, e não ao universo em si mesmo, constituído pela pluralidade dos mundos, no sentido que ao termo "mundo" dava a tradição grega e medieval, significando um todo completo, possuindo em si próprio o seu centro. Não haveria um centro do universo, mas uma multidão de centros, uma para cada sistema solar. 0 do sistema solar a que a Terra pertence está no próprio sol e nãona Terra. Por referência a ele, o homem está em pé de igualdade de outros possiveis seres de idêntica dignidade de que os diferentes mundos possam, porventura, estar povoados (12).

Para o homem que se cria colocado num mundo finito, com seu centro na Terra, onde tudo, por sua vez, teria sido destinado para sua própria existência, serviço e contemplação, um mundo infinito parece despropositado, sem sentido e falho na sua finalidade. Que utilidade poderão ter todas essas estrelas inumeráveis que nem sequer podemosver, seja a olhonu, seja através do mais potente telescópio? Não admira pois que 0 antropocentrismo cristão agarrado a muitas e variadas provas de acção teleológica de Deus no mundo, tenha sido, durante muito tempo, um dos grandes adversários da ideia de um mundo infinito. Afirmar um mundo infinito contra um mundo finito parecia levar à negação da sua finalidade, degradando o mundo reale, dentro dele, degradando o próprio homem, criado à imagem e semelhança de Deus, para ser dele rei e senhor. Nãotardou, porém, que os defensores da infinidade do universo e mesmo muitos dos que crendo na sua finidade admitiam a infinidade como possivel, se não deixassem persuadir por tais arrazoados. "Se a Terra foi destinada para a existência, serviço e contemplação do homem, porque não seriam os outros planetas criados para usos semeIhantes, possuindo cada um deles os seus próprios habitantes dotados de visão e de inteligência?" - interrogar-se-ia Bentley na sua refutação do ateísmo (13).

A nova cosmologia impunha uma nova compreensão do destino do homem em defesa da sua própria dignidade e situação num universo infinito. As mais proeminentes figuras da nova ciência sentiram essa necessidade e a ela não ficaram alheias.

Giordano da Bruno fê-lo expressamente, considerando quer 0 aspecto social, quer 0 aspecto pessoal da problemática gerada (14). Para ele, num universo infinito, a divindade não pode existir senão nas coisas que o compõem. Por isso, os homens, como todas as demais coisas, animadas ou inanimadas, não são senão modalidades transitórias do próprio Deus. Não tem sentido o dualismo Céu-Terra, nem o dualismo Deus-Universo. Ao ser deslocado da sua posição central no universo por negação da própria existência de uma tal posição, a afirmação do Homem no Universo sairia, assim, ainda mais enaltecida: o seu destino não tem 0 universo ao seu serviço; o seu destino confunde-se com o destino do universo.

Mais do que nunca o homem se afirma como um microcosmos, penetrado de toda a espécie de forças cósmicas, capaz de agir sobre simesmo e sobre os outros seres do universo por uma acção de simpatia que liga entre si as diferentes partes do mundo (15).

Kepler (1571-1630) não aceitaria a concepção da infinidade do universo proposta por Bruno que se the afigurava ser mera expressão de um sentimento religioso, fora da alçada da ciência astronómica a que se dedicava, uma ciência rigorosamente confinada ao mundo dos fenómenos físicos. Para Kepler, embora o universo possa ser tão grande quanto o queiramos, não podem existir estrelas - e em qualquer caso estrelas visiveis - separadas de nós por uma distância efectivamente infinita, pois seria necessário que fossem elas próprias de dimensões infinitas para que isso acontecesse. Consequentemente, e de um ponto de vista estritamente fenomenológico, "0 universo, no seu interior, em direcção ao sol e aos planetas, seria necessa- 
riamente finito e, de algum modo, oco. 0 resto pertence à metafísica" (16). A infinidade de um mundo implicaria necessariamente uma uniformidade perfeita da sua estrutura e o seu conteúdo, o que do ponto de vista fenomenológico, seria precisamente o contrário do que observamos: "o aspecto das estrelas fixas, vistas umas das outras é diferente do que é visto do nosso mundo, e estamos mais afastados das estrelas fixas do que elas o estão umas das outras" (17).

Por sua vez, Galileu-Galilei (1564-1642) não deu grande importância à questão da infinidade ou não infinidade do universo, considerando tratar-se de uma questão insolúvel, como expressamente o declara na carta que escreveu, em 1639, a Francesco Ingoli: "e não sabeis que é ainda incerto (e creio que o será sempre para a ciência humana) se o mundo é finito ou, pelo contrário, infinito. Ese ele fosse verdadeiramente infinito, como poderieis vós afirmar que as dimensões da esfera estrelada são proporcionais às da orbis magnum se esta, em relação ao universo, é mais pequena que um grão de milho em relação a ela?" (18).

E repetia-o no Diálogo Sobre os Dois Grandes Sistemas do Mundo (1632), onde Salviati, porta-voz das suas ideias, se dirige contundentemente ao aristotélico Simplicio nestes termos: "nem vós nem qualquer outro provou alguma vez que o mundo seja finito $e$ dotado de uma forma ou, pelo contrário, infinito e interminado" (19). Todavia, na carta que dirigiu, em 1640, a Fortunio Liceti, mostrar-se-ia mais inclinado para a ideia de um universo infinito do que para a ideia de um universo finito: "foram alegadas numerosas e subtis razōes em favor destas concepções, mas nenhuma delas, em minha opinião, conduz a uma conclusão necessária, de modo que permaneço na dúvida quanto à verdade de uma ou de outra destas asserções. Existe um único argumento que me é próprio, que me inclina mais para 0 infinito e 0 interminado (...); sinto que a minha incapacidade de compreender poderia com maior propriedade ser referida à incompreensivel infinidade do que à finidade, onde se não encontra nenhum princípio de incompreensibilidade" (20).

De salientar que o modo um tanto quanto displicente com que Galileu abordou esta questão tanto pode ser fruto do pouco interesse que, de modo geral, votou aos problemas de cosmologia, mais interessado na geometrização da física do que na geometrização do espaço, como de uma atitude de prudência perante a Igreja, face à condenação de Bruno, em 1600 , e de Copérnico, em 1616.

Para Descartes (1596-1656), o mundo real que é o universo é um "mundo de geometria reificada, um mundo matemático rigorosamente uniforme" (21), feito somente de espaço e movimento. 0 espaço identifica-se com a matéria que é ela própria extensão a que não é apenas falso ou absurdo atribuir quaisquer fronteiras, mas também contraditório. Como tal, o mundo é infinito: "a matéria extensa que compõe 0 universo não possui quaisquer limites porque, não importa onde os queiramos simular, podemos imaginar sempre para além deles espaçosindefinidamente extensos, que não somente imaginamos mas concebemos serem na realidade tais como os imaginamos" (22).

Para Descartes, não faz sentido discutir se as estrelas fixas são grandes ou pequenas, se estão distantes ou próximas, pois que distantes ou próximas, elas estão, comonós próprios e como o nosso sol, no meio de outras estrelas sem fim, 0 universo é uma unidade onde o número de sistemas subordinados e ligados entre si é em número indefinido, formando imensos turbilhões ou vórtices de matéria sempre idêntica, que, no espaço ilimitado, se tocam e se limitam uns aos outros. Tanto na extensāo física, como na série dos números, é sempre possível ir mais além sem nunca se alcançar um termo.

"E chamaremos a estas coisas indefinidas em vez de infinitas, a fim de reservarmos apenas para Deus o nome de infinito" (23).

Quer dizer, Descartes distingue entre infinito e indefinido. Infinito só Deus o é; o universo é, antes, indefinido. Esta distinção corresponde, em Descartes, à distinção tradicional entre infinidade actual e infinidade potencial. Somente a respeito de Deus possui o homem garantia clara de que ele é infinito em acto, porque absolutamente perfeito; "quanto às outras coisas, sabemos que elas não são absolutamente perfeitas porque, embora notemos nelas, porvezes, propriedades que nos parecem não ter limites, não deixamos de saber que isso procede da imperfeição do nosso conhecimento $e$ de modo algum da sua natureza" (24). Para Descartes, a infinidade não se conhece pela negação da finidade mas, pelo contrário, é negando o infinito que se concebe o finito. Porém, 0 infinito ultrapassa de tal modo o entendimento humano, que é finito, que não podemos compreendê-lo, nem sequer analisá-lo inteiramente senão em termos de indefinido. E daí que se tornem desprovidas de qualquer valor todas as discussões sobre o infinito, nomeadamente as discussões sobre a composição do contínuo, tão em voga nos finais da Idade Média.

"Nãoé necessário esforçarmonos por compreender 0 infinito, mas somente pensar que tudo aquilo em que não encontramos quaisquer limites é indefinido. Desta maneira, jamais nos enredaremos nas disputas sobre o infinito; tanto mais que seria ridiculo que nós que somos finitos, empreendêssemos determinar qualquer coisa sobre ele e por este meio supô-lo finito ao esforçarmo-nos por compreendê-lo. É por isso que não cuidaremos de responder aos que perguntam se a metade de uma linha infinita é sempre infinita, ou se o número infinito é ou não par, e outras coisas semelhantes, dado que apenas aos que crêem que 0 seu espírito é infinito parece deverem ser examinadas tais dificuldades" (25).

0 universo é infinito porque não é possivel assinalar-lhe quaisquer limites. Sem limites, ele é um universo aberto.

Newton (1642-1727) escreveu, como matemático, sobre o movimento

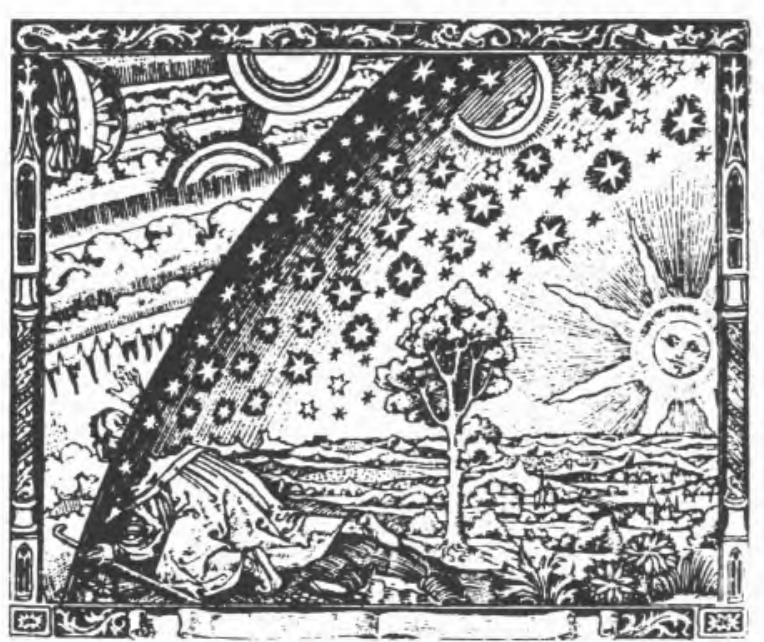




\section{artigos}

eterno, uniforme e rectilíneo de um corpo. A ideia de eternidade possível de um movimento tem subjacente a ideia de um universo infinito. 0 movimento não pode ser infinito se confinado a dimensōes finitas. No universo finito dos Antigos, à dimensão finita das esferas celestes, correspondia uma velocidade finita. Só relativamente a um espaço sem limites se pode conceber um movimento eterno (26). Mais. Só um espaço infinito explicaria -

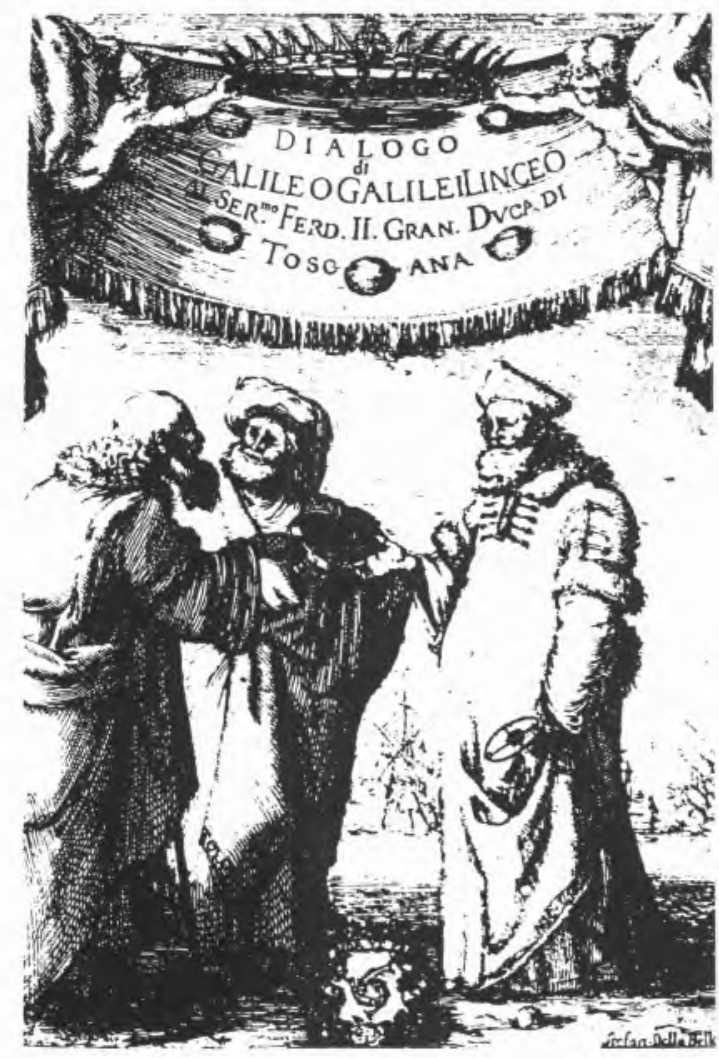

segundo Newton-a actual composição do universo: "se toda a matéria do nosso sol, e toda a matéria do universo, estivessem igualmente dispersas através de todos os céus, e cada partícula possuisse uma gravidade inata em direcção a tudo o resto, e todo o espaço através do qual esta matéria estivesse dispersa fosse apenas finito, a matéria situada nos confins deste espaço tenderia, pela sua gravidade em direcção a toda a matéria colocada no interior e, consequentemente, cairia em direcção ao centro do espaço inteiro, e formaria aí uma grande massa esférica. Mas se a matéria estivesse igualmente distribuída através de um espaço infinito, ela jamais se poderia reunir numa só massa; parte dela reunirse-ia numa massa, enquanto outra parte se reuniria noutra massa, de modo a formar um número infinito de grandes massas, a grandes distâncias umas das outras através deste espaço infinito" (27).

A ciência e filosofia newtonianas, na sua forma genérica da chamada teoria da gravitação universal, conquistaram tapidamente o mundo científico, pese embora a resistência dos discípulos de Descartes e outros filósofos do Continente. Por volta do fim do século XVII, ela estava definitivamente bem implantada em todo o mundo culto ocidental. 0 universo da sua cosmologia é um universo homogéneo e infinito na duração e na extensão, no qual a matéria eterna, de acordo com leis eternas e necessárias, se move sem fim e sem objectivo, no espaço eterno. 0 s seus atributos ontológicos são, portanto, os atributos do próprio Deus.

Com Newton, o universo passou a ser pensado como um grande relógio mecânico posto em movimento no início dos tempos pela mão divina e depois abandonado às leis nele inscritas.

Assim o encararam, entre muitos outros pensadores de renome, N. Malebranche (1638-1715), G. W. Leibnitz (1646-1716) e Pierre Simon, Marquês de Laplace (1749-1827).

Neste Universo, dos maiores aos mais pequenos movimentos, toda a criação evolui de uma forma que pode ser prevista com precisão absoluta pelas leis de Newton, pois nada é deixado ao acaso. 0 futuro é totalmente determinado pelo passado. Tudo o que acontece está pré-determinado. 0 universo objectivo existe independentemente da vontade e da finalidade do homem. Este integra-o em estrito acordo com as leis eternas que o regem. A rigidez do determinismo a que estas leis conduzem confere ao homem um sentimento de particular segurança acerca do seu lugar no universo, seja este povoado ou não por outos seres inteligentes.

Não obstante as dificuldades de primeira hora, os grandes avanços científicos do século XIX, particularmente os relacionados com a teoria do calor, a teoria da luz como onda electromagnética, e os demais fenó- menos eléctrico-magnéticos em geral, foram construidos no âmbito do quadro conceptual de uma física determinista, logicamente radicada na física clássica newtoniana.

Nos fins do século XIX e princípios do século $\mathrm{XX}$, o desenvolvimento da teoria sobre a estrutura atómica da matéria, levaria ao ruir parcial dessa imagem determinista do universo. Com efeito, as unidades atómicas da matéria revelavam um comportamento aleatório e incontrolável que a física determinista de Newton não permitia descrever satisfatoriamente. E tornou-se óbvio que não era possivel compreender cabalmente o início e o fim do universo sem ir além da teoria da gravitação de Newton. Assistiu-se à formulação, primeiro, da teoria da Relatividade Restrita (1905), e, depois, em 1916, à formulação da teoria da Relatividade Geral, uma e outra da autoria de Einstein; e assistiu-se, também, à formulação da teoria quântica, no decorrer dos anos de 1900 a 1926.

Formularam-se novas questões sobre a natureza do universo. Especificamente, estudando a sua imensidade, com ênfase na geometria, a Teoria da Relatividade Geral formulou uma nova visão da natureza. Em 1922, o físico soviético Alexander Friedman resolveu as equações da Relatividade Geral de Einstein referidas ao próprio universo, imaginado como um gás uniforme em que as partículas seriam as galáxias As soluções encontradas para essas equações implicavam que 0 universo não podia ser estático. 0 Universo é um universo em evolução; o gás das galáxias tinha de se expandir ou de se contrair.

A energia total de qualquer galáxia componente deste gás de galáxias é dada por $m R^{2}\left(1 / 2 H^{2}-4 / 3\right.$ $\pi \rho \mathbf{G})$ onde $\mathbf{m}$ é a massa da galáxia, $\mathbf{R}$, a sua distância relativamente a um centro de referência do meio em que existe, $\mathbf{H}$ a constante de Hubble, $\rho$, a densidade de massa cósmica e $\mathbf{G}$, a constante de gravitação de Newton. As galáxias escapar-se-ão para o infinito, e teremos um universo em expansão, desde que a sua energia seja positiva. Para E (energia) $=0$, define-se a velocidade de escape da galáxia, correspondendo à situação em que $1 / 2 \mathrm{H}^{2}=4 / 3 \pi \rho \mathrm{G}$, ou seja, à chamada densidade crítica dada por $\rho=3 \mathrm{H}^{2} / 8 \pi \mathrm{G}$. Para um valor de $\mathrm{H}=15$ $\mathrm{Km}$ por segundo por milhão de anosluz, obtém-se um valor de $\rho$ da ordem 
dos $4,5 \times 10^{-30}$ gramas por centimetro cúbico. Ora a densidade de massa cósmica actual é da ordem de $2,7 \times 10^{-6}$ particulas nucleares por centímetro cúbico o que significa que a energia de qualquer galáxia é positiva, ou seja, que as galáxias se estão a afastar cada vez mais umas das outras (28). Neste sentido, o universo em que vivemos é realmente um universo aberto e, como tal, infinito.

Com 0 arrefecimento progressivo que se foi operando no universo, após a explosão inicial, a densidade de energia radiante foi decrescendo e a densidade de matéria aumentando. Uma e outra poderão ter existido em quantidades idênticas após os primeiros 250 milhões de anos da existência do universo. A partir de então, a densidade da matéria passou a ser superior à densidade de energia radiante, tornando possivel uma diferenciação progressiva na homogeneidade inicial dogás-galáctico, o ylem a que se refere G. Gamow (1904-1968) (29).

De notar aqui que, a principio, Einstein não acreditou nos cálculos de Friedman e pensou que ele se tivesse enganado. Acreditando que o universo existia desde sempre e para sempre, $\mathrm{e}$ aceitando também a sua infinidade espacial, Einstein, tal como a maioria dos físicos e astrónomos do seu tempo, cria que o universo era estático. Um universo dinâmico e com evolução parecia-Ihes contrário a toda a experiência, e uma novidade artificial. Verificada a exactidão dos cálculos de Friedman, como acreditava que 0 universo era estático, Einstein foi ao ponto de alterar as suas equaçōes da relatividade, acrescentando-lhes um "termo cosmológico" que permitia uma solução estática. No quadro dos seus principios relativistas que davam conteúdo inteiramente novo às ideias de espaço, tempo e matéria relativamente às que informavam a mecânica da física clássica, esse termo cosmológico permitia-the concordar com Newton em que o movimento do universo estava completamente determinado desde o passado infinito até ao futuro também infinito.

Em 1927, G. H. Lemaitre (18941966) demonstraria categoricamente que 0 universo em expansão está totalmente de acordo com a teoria da relatividade. A partir de um "átomo primitivo", sem estrutura mecânica e sem movimentos internos, pura con- densação de todas as potencialidades energéticas e de todas as formas atómicas virtuais implicadas no desenvolvimento futuro, o universo terse-ia organizado estruturalmente graças a uma explosão inicial superradioactiva, em duas fases sucessivas de expansão separadas por uma instabilidade gravitacional (30). Einstein acabaria por aceitar a ideia de um universo em expansão, confessando, então, que o termo cosmológico que introduzira nas equaçōes da relatividade tinha sido "o maior disparate" da sua vida.

Em 1929, 0 astrónomo americano Edwin Hubble (1889-1953), com base num estudo pormenorizado das galáxias distantes, concluiria que o universo em que vivemos é, de facto, um universo em expansão, uma expansão determinada pelo afastamento mútuo das galáxias, quer pela produção, sob o efeito da interacção dos fotões com 0 campo espacial, de um conjunto de modificações que poderão alterar a métrica do espaço, quer pelo crescimento do espaço por dentro, correspondente, por reflexo e formalmente, a uma fuga real das galáxias (31).

Hoje, a maioria dos físicos e astrónomos aceita a teoria do universo em expansão, contra alguns defensores dos chamados modelos estáticos do universo, nomeadamente os defensores da chamada cosmologia da criação contínua proposta por H. Bondi, T. Gold e F. Hoyle da Universidade de Cambridge, em 1948 (32). Para os defensores do universo em expansão, o universo infinito e aberto defendido pela cosmologia heliocentrista do Renascimento, na negação do geo-e do antropocentrismo dos Antigos, é, além disso, um universo dinâmico.

\section{DETERMINISMO E INDETERMINISMO}

Como notámos, a tentativa de Einstein de conciliar o carácter estático do universo com a teoria geral da relatividade era a salvaguarda do quadro determinista da física clássica. A ideia de que o mundo não existe independentemente da nossa observação, isto é, que a realidade possa, em parte, ser criada pelo observador, inerente, de algum modo, à teoria da Relatividade Geral aplicada às partículas quânticas, é, em si mesma, uma ideia chocante e dai que haja dentro de nós algo que se recusa tenazmente a aceitá-la de boa-vontade, como realidade inevitável. Einstein opôs-se-the com decisão. Se tal ideia se constituiu em "dogma" da ciência donosso tempo, poderíamos então dizer que Einstein quase morreria impenitente pois que, quase até ao fim da sua vida sustentou que o universo é

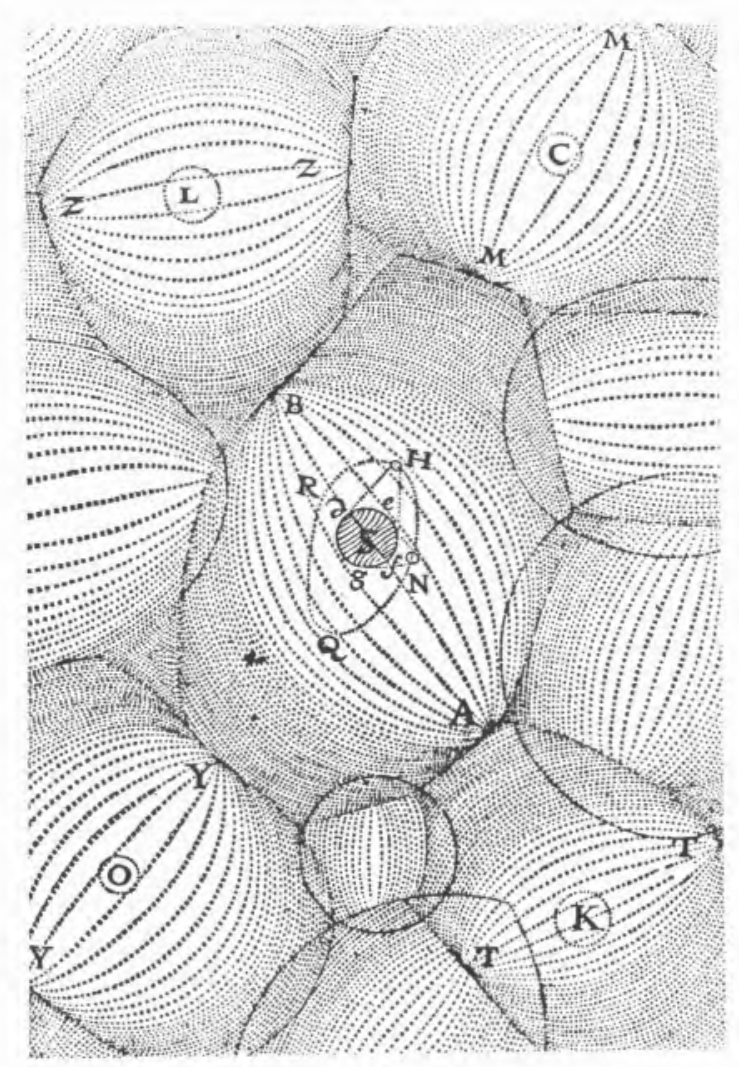

indiferente à humanidade $\mathrm{e}$ aos seus problemas, como a natureza é indiferente às opções humanas.

As reservas que se põem à sua "impenitência" até final ajudam a melhor compreender a sua posição. Em carta para Max Born, datada de 31 de Março de 1954 (um ano antes da morte de Einstein!), W. Pauli dá conta de conversas que tivera ultimamente com Einstein, em Princeton, referindo nomeadamente, que Einstein não considerava já o conceito de "determinismo" tão fundamental quanto frequentemente ele é tido por ser. Textualmente, Pauli escreve: "o ponto de partida de Einstein é "realista" e não "determinista", o que significa que o seu preconceito filosófico é diferente" (33). Por sua vez, na sua autobiografia 
intelectual, Popper refere, a propósito de uma visita que fizera a Einstein, em 1950: "o tópico principal da nossa conversa foi o indeterminismo. Tentei convencê-lo a abandonar o seu determinismo, que equivalia à ideia de que o mundo era um universo-bloco parmenidiano tetradimensional no qual a mudança era uma ilusão humana, ou perto disso. (Ele concordou que a sua perspectiva tinha sido essa, e, enquanto a discutiamos, chamei "parménides" a Einstein). Argumentei que se os homens ou outros organismos podiam ter experiência da mudança e da autêntica sucessāo do tempo, então isso era real. Não se podia afastar explicando-a por uma teoria do sucessivo surgimento à nossa consciência de porções do tempo que num certo sentido coexistem; é que essa espécie de "surgimento à consciência" teria precisamente o mesmo carácter que a sucessão de mudanças que a teoria tenta explicar e afastar. Introduzi também os argumentos biológicos, de certo modo óbvios: que a evolução da vida e a maneira como os organismos se comportam, especialmente os animais superiores, não se pode verdadeiramente compreender com base em qualquer teoria que interprete o tempo como se ele fosse algo como outra coordenada espacial(anisotrópica). De resto nós não temos experiência das coordenadas espaciais. E é por isso que elas são muito simplesmente inexistentes: temos de ter cuidado para não as hipostasiarmos: são constru-

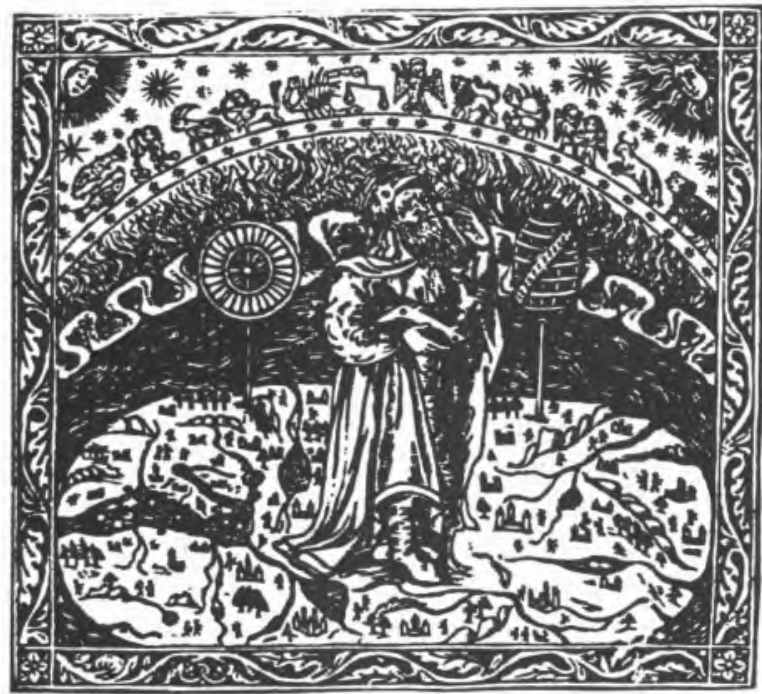

ções quase totalmente arbitrárias. Por que é que então haveríamos de ter experiência da coordenada tempo decerto a única adequada ao nosso sistema inercial-não só como real mas também como absoluta, isto é, como inalterável e independente de qualquer coisa que possamos fazer, a nāo ser mudar o nosso estado de movimento?" (34).

Mais adiante, Popper continua: "ora, eu tentei apresentar a EinsteinParménides, com tanta força quanto me foi possivel, a minha convicção de que se deve tomar uma clara posição contra qualquer visão idealista do tempo. E tentei também mostrar que, ainda que a visão idealista fosse compativel tanto com o determinismo como com o indeterminismo, se devia tomar uma posição clara a favor de um universo "aberto" - um universo no qual o futuro não estivesse em sentido nenhum contido no passado ou no presente, se bem que estes the impusesse severas restrições. Argumentei que não nos deviamos deixar dominar pelas nossas teorias e ser levados a abandonar o senso comum com demasiada facilidade. Era evidente que Einstein não queria abandonar o realismo (a favor do qual os argumentos mais fortes se baseavam no senso comum), ainda que ache que ele estava disposto a admitir, tal como eu, que um dia poderíamos ser forçados a abandoná-lo se fossem avançados argumentos muito poderosos (do tipo do de Godel, digamos) contra ele" (35).

Semnegarminimamente ovalor do génio científico de seu mestre e fautor que foi Einstein, a ciência do séculoXXnãohesitou, todavia, no trilhar de caminhos diferentes. Como Karl Popper o tem frisado, em diversas circunstâncias, o universo aberto tornou-se o termo de referência de argumentaçăo decisiva a favor do indeterminismo e o requisito de uma sociedade fundada sobre a liberdade, a criatividade e a racionalidade do homem. 0 s próprios títulos de algumas obras científicas deste proeminente filósofo da ciência de nossos dias, apresentadas como pré-escritos à sua Lógica da Descoberta Cientifica (36a) são por si só elucidativos: 0 Universo Aberto, Argumentos a favor do Indeterminismo (34) e Sociedade Aberta, Universo Aberto (36b).

Todavia, impõe-se notar que universo aberto não tem aqui exactamente o mesmo significado que antes referimos. Estritamente determinista, o universo infinito da física clássica é um universo aberto no sentido que não é possível assinalarIhe quaisquer limites ontológicos, no espaço e no tempo; não o é, no entanto, do ponto de vista metafísico e lógico, pois é causalmente fechado.

A formulação mais clara do determinismo físico subjacente à física clássica deve-se a Laplace, com base na mecânica de Newton. De acordo com ele, dadas a massa, posição e velocidade exactas de todas as particulas do universo num momento de tempo, é possivel calcular, usando as leis da mecânica newtoniana, tudo 0 que alguma vez nele aconteceu no passado e tudo o que virá a acontecer no futuro, incluindo todos os movimentos físicos de todos os homens. Para tanto, bastaria dispor de uma máquina suficientemente potente para comportar a complexidade dos cálculos envolvidos, e uma inteligência suficientemente superior para os equacionar.

Este determinismo rigoroso de Laplace teve de ser modificado perante a ruína de algumas tentativas de Maxwell para reduzir os fenómenos eléctricos e magnéticos à mecânica de Newton. Recorreu-se, então, a um modelo mecânico do éter. Com essas tentativas ruiu também a tese do carácter fechado do mundo da física, embora a tese fundamental do determinismo universal não tenha sido muito afectada. Só com a mecânica quântica, ele seria radicalmente posto em causa.

Segundo a mecânica quântica, há processos físicos elementares, v.g., as transições electrónicas nos átomos, causalmente irredutiveis, isto é, que não são analisáveis em termos de cadeias causais; são os chamados "saltos quânticos, acontecimentos imprevisiveis, não controlados nem por leis naturais, nem pela coincidência de leis causais, mas só por leis probabilisticas". Concretamente, não existe nenhuma lei física que nos diga exactamente quando é que uma transição electrónica vai ocorrer; o máximo que podemos fazer, no domínio deste tipo de transiçōes é determinar a probabilidade de uma dada transição ocorrer (37). Tais acontecimentos não são prédeterminados e não podem, portanto, ser previstos com toda a precisão, por muito grande que seja o nosso conhecimento de todas as condições 
relevantes anteriores ao acontecimento. A sua imprevisibilidade plena é intrínseca à sua própria natureza e não apenas epistemológica. Acerca de tais processos, só previsões estatísticas testáveis são possiveis (38).

0 carácter indeterminista de certos processos físicos elementares considerados na base da mecânica quântica torna-se mais patente com a introdução do conhecimento humano objectivo no universo físico, fazendo ressaltar o que Popper designou por a "essencial abertura ou inacabamento" (incompleteness) desse mesmo universo. Na sua totalidade, que inclui a vida e a consciência, a Natureza não pode ser totalmente pré-determinada (39). 0 universo que contém o conhecimento humano como parte dele é, forçosa e intrinsecamente, um universo "parcialmente causal, parcialmente probabilístico, parcialmente aberto"; é usando a terminologia de Karl Popper, um universo emergente, onde a liberdade humana, fazendo parte efectiva da natureza, a transcende.

Do ponto de vista das ciências exactas, é particularmente relevante o carácter indeterminista de certos processos elementares considerados na base da mecânica quântica. Sobre ele nos debruçaremos com mais algum pormenor, referindo as características fundamentais da chamada "peculiaridade quântica" (40).

A teoria quântica nega a ideia de objectividade imanente à física clássica, e não deixa lugar para a imagem determinista do mundo. 0 que acontece no mundo quântico, o micromundo, não obedece a leis deterministas. Além disso, depende da forma como é observado, isto é, não existe independentemente da observação; 0 que existe depende, em parte, daquilo que 0 observador decide observar. 0 micromundo é mera fantasia se não for observado. Como o disse um dia John Wheeler, no mundo quântico "nenhum fenómeno é fenómeno até ser fenómeno observado" (41).

Embora contrários ao mais elementar sentimento de um certo realismo ingénuo sequioso de uma total coincidência entre o mundo das aparências e o mundo da realidade, estes postulados-chave da teoria quântica são matematicamente coe-rentes e concordam espectacular-mente coma experiência, por mais que possam não satisfazer o espírito científico.
Felizmente, temos apenas de nos preocupar com a realidade determinada pelo observador para objectos de dimensões quânticas, já que existe uma diferença qualitativa importante e essencial entre o micromundo e o macromundo: enquanto este pode acumular informação, naquele tal não acontece. Quer dizer, no micromundo dos quanta, a realidade é uma distribuição aleatória de acontecimentos que o observador, no próprio acto de observar, transforma noutra igualmente aleatória. Nele, não têm significado acontecimentos isolados. Consequentemente, a teoria da medida quântica é uma teoria da informação: o mundo quântico confunde-se com aquilo que sobre ele podemos saber. $E$, por isso, não é possivel adaptar a realidade quântica à realidade clássica, onde os acontecimentos individuais, no espaço e no tempo, são possíveis e existem (42).

Porque a intencionalidade humana influencia a estrutura do mundo físico, com carácter determinante no mundo quântico, e porque, como já 0 dissemos, a liberdade humana, embora nela inserida, transcende a natureza, a teoria quântica rejeita 0 determinismo laplaciano. Em vez dele, aceita a natureza estatística da realidade. Esta aceitação é o essencial da chamada interpretação da mecânica quântica consagrada pela escola de Copenhaga que embora aceite pela maioria dos físicos, teve à partida a reserva de muitos deles e a tenazoposição de Einstein que, inclusivamente, durante vários anos, imaginou diversas experiências conceptuais que mostrassem alguma falha subjacente a tal interpretação, qual, por exemplo, a conhecida experiência conceptual do relógio dentro de uma caixa (43) com que supôs mostrar a violação flagrante da relação de indeterminação de Heisenberg energia-tempo, $\Delta \mathrm{Ex} \Delta \mathrm{t}>\mathrm{h}$. A refutação dos resultados dessas "experiências", em que se empenhou particularmente Bohr, fez com que Einstein deixasse de contestar a coerência interna da teoria quântica na sua interpretação de Copenhaga; não o convenceu, todavia, a aceitar que a teoria quântica assim assumida desse uma descrição completa e objectiva da natureza. Até ao fim da sua vida, em 1955, Einstein acreditaria que o universo é indiferente à humanidade $\mathrm{e}$ aos seus problemas $\mathrm{e}$ que Deus não joga aos dados. Não

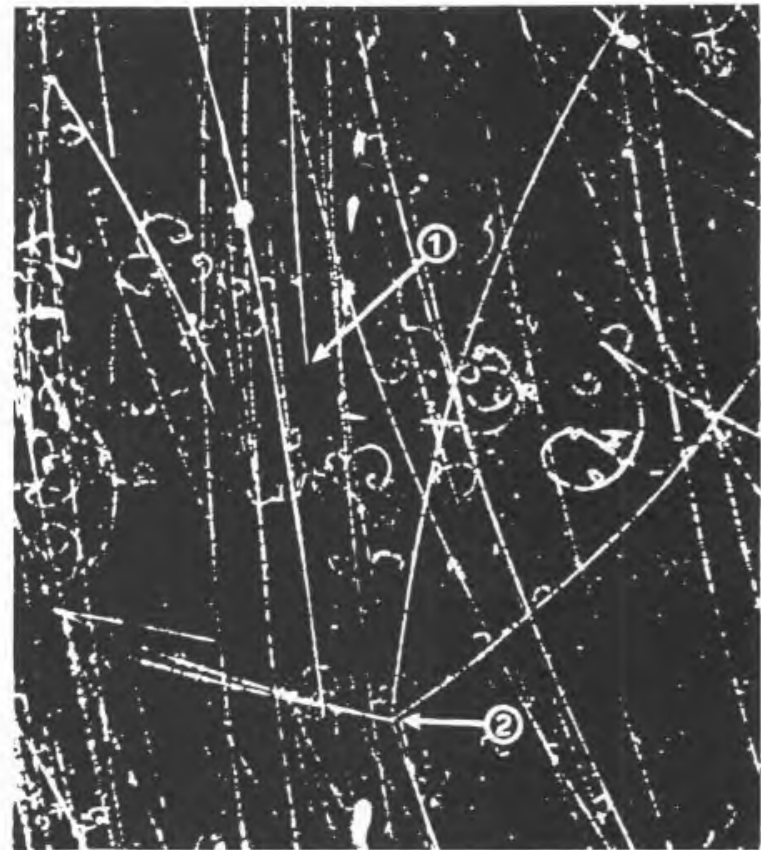

obstante, a interpretação de Copenhaga generalizou-se, afirmou-se e ganhou raízes sólidas no mundo científico.AMecânica Quântica tornouse rapidamente, nas mãos de uma pleíade de jovens físicos, muitos deles menos interessados nos problemas de interpretação do que nas suas aplicações, no mais poderoso instrumento matemático para a explicação dos fenómenos naturais, em física, em química e em biologia, provando à saciedade que a negação do determinismo rígido dos fenómenos da natureza não significava 0 fim da ciência, nomeadamente o fim da física ou da química.

Confrontados com o acaso que reina no interior da matéria, os cientistas tiveram de proceder ao estabelecimento de uma nova visão da realidade mas não ficaram minimamente cerceados, nem impossibilitados, no prosseguimento de sua missão científica. Empenhada em tornar os fenómenos naturais imediata ou directamente compreensiveis à nossa maneira de pensar, pela descoberta experimental e estabelecimento teórico da ordem conceptual subjacente à toda a natureza, à ciência moderna poderá ter parecido, por um momento, ser impossivel prescindir do rígido determinismo fenoménico, fundamento 


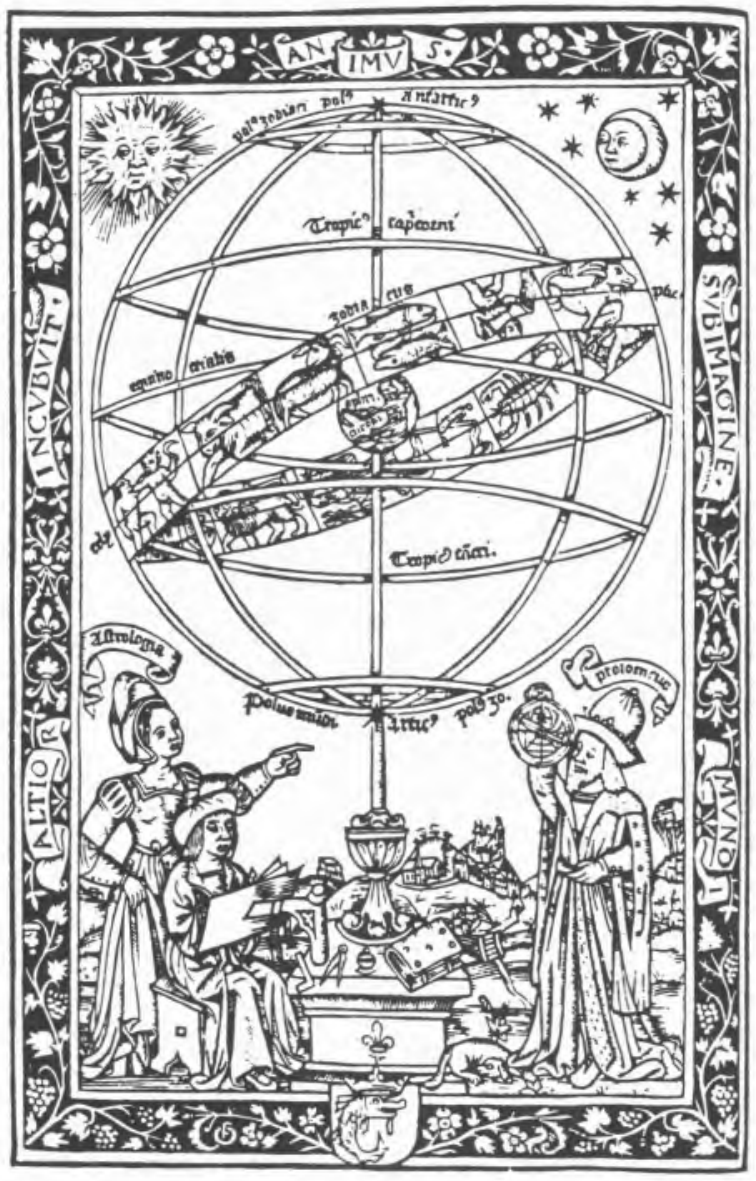

objectivo da lei e da racionalidade do universo. E dai a confusão que frequentemente se gerou, em alguns meios, entre a negaçāo de um universo causalmente fechado e um universo a-causal (44).

A afirmação do acaso que domina os fenómenos do mundo microfísico não pode ser tomada no sentido de uma concepção negativa do acaso, isto é, no sentido de se admitir que algo possa acontecer sem qualquer causa ou lei. Dizer que o mundo dos fenómenos quânticos está informado com uma existência inegável e objectiva, representando "a ideia de um encontro entre factos racionalmente independentes uns dos outros, encontro que é em si próprio puro facto ao qual não podemos atribuir nem lei, nem razão" nem, consequentemente, prever (45).

Nesta acepção, o acaso aparece-nos como uma coincidência não teleológica e uma irregularidade factual surgida no seio da regularidade, devido ao embate de duas ou mais séries fenoménicas autónomas, com carácter não-repeticional. 0 indeterminismo do mundo quântico não se reduz a mera questão da capacidade de conhecimento a que a omnisciência de um qualquer demónio laplaciano, capaz de comportar todas as leis universais, bem como todas as condições iniciais relevantes e todos os métodos de cálculo lógico-matemático, para todo e qualquer sistema, retiraria todo o sentido. Não. Nenhum sistema físico pode ser completamente previsto a partir de dentro, com qualquer grau especificado de precisão, independentemente da capacidade cognoscitiva, mesmo que infinita, do observador que sobre ele se debruce, porque o domina o acaso, fortuito e imprevisivel, cuja "lei" por que se rege não pode ser definida senão em termos de probabilidades. A mecânica clássica não comporta, todavia, tal tipo de lei, pois que na mecânica clássica, quando se formula uma lei, postula-se "ipso facto" e no mesmíssimo instante, o determinismo. Nela, não se prova 0 determinismo provando a lei, pois ela própria é já o determinismo aceite (46). A formulação de leis cientificas com valor meramente probabilistico implicava a reformulação do próprio conceito de lei.

Porque não possuímos 0 absoluto do saber, não só por limitação da nossa capacidade de intelecção e conhecimento, mas também por que a realidade fenoménica comporta dados variados sem conexão causal, a nossa previsão torna-se meramente probabilistica; a lei torna-se antes hipótese útil de trabalho cuja validade reside numa contínua repetição verificada, isto é, na frequência da sua confirmação pelos fenómenos naturais.

Por isso Karl Popper afirma que "o argumento decisivo a favor do indeterminismo é a existência do próprio conhecimento racional"; "a progres- siva racionalização do mundo - a tentativa de agarrar o mundo na rede do conhecimento - tem limites, a qualquer momento, no próprio conhecimento do conhecimento que tambémé, é claro, um processo que pertence ao mundo" (47). Uma inteligência infinita, no seu exame exaustivo do mundo, poderia produzir uma rede mais apurada, mas nem por isso poderia atingir o limite último da malha possivel, que também ele se estende até ao infinito.

Ao afirmar a "lei" como hipótese de trabalho que tira a sua validade de uma contínua repetição verificada, a ciência que com este tipo de leis se faz, é ela própria uma ciência aberta, feita de teorias em joeiração permanente e em controvérsia que busca detectar seus erros e reduzir 0 seu campo de ignorância. Feitas de racionalismo crítico, céptico e experimentalista, as coordenadas da ciência que leva em conta 0 indeterminismo não são de molde a ser garante daquele tipo de certeza que só a fé pode assegurar ao homem. A ciência é, como o universo cuja inteligibilidade tenta abarcar, uma ciência aberta (48). A Natureza recusa exprimir-se na linguagem que qualquer tipo de regras confinadas a um paradigma rigoroso e estrito supõem e, consequentemente, de geração em geração, a ciência está sujeita a contínua mutabilidade, nem necessariamente irreversivel, nem necessariamente unidireccional.

Ao aceitar 0 acaso reinante no comportamento mais íntimo da matéria, a ciência do século XX que havia já resolvido até aos alicerces os conceitos de tempo e espaço, de éter e de inércia, de massa e gravitação, estendeu a sua revolução aos conceitos de lei e de causa. Porque todo o determinismo dissimula uma real indeterminação existente no microcosmos dos quanta, as leis físicas não traduzem o conhecimento exacto das causas dos fenómenos naturais a que se referem. Nem por isso deixam de os representar cabalmente no domínio da escala macroscópica; não comportam a individualidade $\mathrm{e}$ isolabilidade das particulas, mas conjuntos estatísticos das mesmas. Nem por isso a ciência que sobre elas assenta perde a sua validade ou se revela menos útil e necessária na sua missão de conhecimento da Natureza. 


\section{NOTAS BIBLIOGRÁFICAS}

(1) Gen. I, 26-29.

(2) Aristóteles, De Coelo, Lib. II, Lect. 26, parags. 101-102; Manuel de Gois, Commentarii Collegii Conimbricensis Societatis Jesu in Quatro Libros de Coelo Aristotelis Stagiritae, Lisboa, 1593, pg. 335.

(3) I. Prigogine e I. Stengers, A Nova Aliança, Ed. Gradiva, Lisboa, 1987, Col. Ciência Aberta, 14, pg. 128.

(4) Nicolau de Cusa, De Docta Ignorantia, Liv. II, Cp. II, pp. 99 ss in Opera Omnia, Ed. E. Hoffman e R. Klibansky, Vol. I. Lipsiae, 1932

(5) A. Koyré, Do Mundo Fechado ao Universo Infinito, Ed. Gradiva, Lisboa, Col. Trajectos, 6, pp. 13-14.

(6) João C. Espada, Liberdade ou Virtude in Revista Expresso, 14 Março 1987, 47-R.

(7) A. Koyré, 0. Cit., pg. 7.

(8) Nicolau de Cusa, 0. Cit., Liv. II, Cp. II, pg. 105.

(9) Ibidem, pg. 104.

(10) Giordano Bruno, Acerca do Infinito, do Universo e dos Mundos, Ed. Fundação Calouste Gulbenkian, Lisboa, 1958, Arg. Diálogo V, pg. 20.

(11) Ibidem, pg. 36 .

(12) (a) Steven J. Dick, Plurality of Worlds. The origins of the extraterrestrial life debate from Democritus to Kant, Cambridge University Press, Cambridge, 1982; (b) Michael J. Crowe, The Extraterrestrial Life Debate, 1750-1900: The Idea of a Plurality of Worlds from Kant to Lowell, Cambridge University Press, Cambridge, 1986; (c) James Trefil, Alone in the Universe in Sciences, vol. 23, 1983, pp. 16-19.

(13) Sir Richard Bentley, Eight sermons preach'd at the Honourable Robert

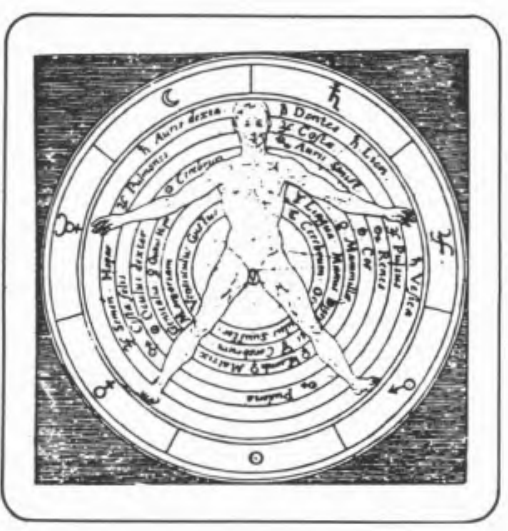

Boyle Lecture in the First Year MDCXCII, Londres, 1963.

(14) Giordano Bruno, Spaccio de la Bestia Trionfante, Stampato in Parigi, Londres, 1584; De Gl' Heroici Furori, Parigi, Apresso Antonio Baio, 1585.

(15) Emile Namer, L'Univers de Giordano Bruno et la Destinée Humaine in L'Univers à la Renaissance, Microcosme et Macrocosme, Presses Univ. de Bruxelles, Bruxelles, 1970, pp. 89-120

(16) J. Kepler, De Stella Nova in Pede Serpentarii, Ed. Praga, 1606, cp.XXI,pg. 691.

(17) J. Kepler, Epitome Astronomiae Copernicanae in Opera Omnia, Ed. Frisch, Frankofurti et Erlangae, vol. VI, 1859, Part. II, pg. 138.

(18) Galileu-Galilei, Lettera a Ingoli in Opere, Ed. Naz. Vol. VI, Florença, 1896, pp. 518 e 529 .

(19) Galileu-Galilei, Diálogo sobre os Dois sistemas do mundo in Opere, Ed. Naz., Vol. VII, Florença, 1897, pg. 315.

(20) Galileu-Galilei, Lettera a Liceti in Opere, Ed. Naz., Vol. XVIII, Florença, 1906, pp. 293ss.

(21) R. Descartes, Principia Philosophiae in Oeuvres, Ed. Adam-Tannery, Vol. VIII, Paris, 1905, Part. II, parag. 4, pg. 42.

(22) R. Descartes, Ibidem, Part. II, parag. 21 , pg. 52

(23) Ibidem, Part. II, parag. 27, pg. 55.

(24) Ibidem, Part. II, parag. 27, pg. 55.

(25) Ibidem, Part. I, parag. 26, pg. 54.

(26) I. Bernard Cohen, 0 Nascimento de uma Nova Fisica, Ed. Gradiva, Col. Trajectos, 10, Lisboa, 1988, pg. 198.

(27) Four Letters from Sir Isaac Newton to the Reverend Dr. Bentley, carta I, Londres, 1756, pp. 203ss.

(28) Steven Weinberg, Os Três Primeiros Minutos, Ed. Gradiva, Col. Ciência Aberta, 20, Lisboa, 1987, pp. 188-189; Robert Smith, The Expanding Universe. Astronomy's 'great debate' 1900-1931, Cambridge University Press, Cambridge, 1982.

(29) G. Gamow, (a) The Creation of the Universe, Viking Press, New York, 1952; (b) My World Line, Viking Press, New York, 1970.

(30) P. Vicentio Arcidiacono, Origem e Evolução do Universo segundo G. Lemaître, Braga, 1958, pg. 6.

(31) Ibidem, pg. 21

(32) H. Bondi, Cosmology, Cambridge University Press, Cambridge, 1960; Fred Hoyle, (a) - The Nature of the Universe, Oxford, 1950; (b) - Galaxies, Nuclei and Quasars, Heineman, Londres, 1965; (c) . From Stonehenge to Modern Cosmology, Freedman, S. Francisco, 1972; (d) - 0
Universo Inteligente, Ed. Presença, Lisboa, 1984

(33) The Born-Einstein Letters, New York, 1971, pg. 221

(34) Karl R. Popper, Universo Aberto, Argumentos a Favor do Indeterminismo, Publ. D. Quixote, Col. Opus, 6, Lisboa, 1988, pp. 24 25.

(35) Ibidem, pg. 25

(36) Karl R. Popper, (a) - The Logic of Scientific Discovery, Hutchinson, Londres, 1959; (b) - Sociedade Aberta, Universo Aberto, Publ. D. Quixote, Col. Opus, 4, Lisboa, 1988.

(37) Heinz R. Pagels, 0. Cit., pp. 76 77 pp. $123-125$.

(38) Karl R. Popper, Universo Aberto,

(39) Sir A. S. Eddington, (a) - The Nature of Physical World, Cambridge University Press, Cambridge, 1932, pp. 293ss; (b) - Stellar Movement and the Structure of the Universe, MacMillan and Cie., Londres, 1914; (c) - The Expanding Universe, Ann Arbor Paperback, Univ. Michigan Press, Michigan, 1958.

(40) Heinz R. Pagels, 0. Cit., pp. 76 77; $112-120 ; 220-226$.

(41) J. Wheeler citado in H. Pagels, 0. Cit., pg. 113.

(42) Heinz R. Pagels, 0. Cit., pp. 221 226.

(43) Einstein supôs que tinha um relógio dentro de uma caixa fechada à prova da luz, com a possibilidade de abrir e fechar muito rapidamente um orifício nessa caixa. Dentro da mesma caixa ter-se-ia também um gás de fotões. Quando se abrisse 0 orifício, um só fotão sairia da caixa. Pesando a caixa antes e depois da abertura do orifício seria possivel determinar a massa e, consequentemente, a energia do fotão que saira. Seria assim possivel determinar simultaneamente e com a precisão desejada a energia e o instante de saída do fotão (cf. Heinz R. Pagels, 0. Cit., pg. 115).

(44) Silvio Lima, 0 Determinismo, o Acaso e a Previsão na História, Coimbra Editora, Col. Universitas, 22, Coimbra, 1958, pp. 17-19.

(45) Ibidem, pg. 17

(46) Ibidem, pg. 19

(47) Karl R. Popper, Universo Aberto, pg. 89 .

(48)I. Prigogine e I. Stengers, 0. Cit. pp. 387 ss.

* Dept. Química - Universidade 3000 Coimbra 